\title{
The importance of clinician, patient and researcher collaborations in Alport syndrome
}

\author{
Michelle N. Rheault ${ }^{1}$ - Judith Savige ${ }^{2} \cdot$ Michael J. Randles $^{3} \cdot$ André Weinstock $^{4} \cdot$ Melissa Stepney $^{5} \cdot$ A Neil Turner $^{6}$. \\ Gina Parziale ${ }^{4}$. Oliver Gross ${ }^{7}$. Frances A Flinter ${ }^{8} \cdot$ Jeffrey H Miner $^{9} \cdot$ Sharon Lagas $^{4} \cdot$ Susie $^{\text {Gear }}{ }^{10}$. \\ Rachel Lennon ${ }^{3,11}$
}

Received: 24 February 2019 / Accepted: 15 March 2019 /Published online: 1 May 2019

(C) The Author(s) 2019

\begin{abstract}
Alport syndrome is caused by mutations in the genes COL4A3, COL4A4 or COL4A5 and is characterised by progressive glomerular disease, sensorineural hearing loss and ocular defects. Occurring in less than 1:5000, Alport syndrome is a rare genetic disorder but still accounts for $>1 \%$ of the prevalent population receiving renal replacement therapy. There is also increasing awareness about the risk of chronic kidney disease in individuals with heterozygous mutations in Alport syndrome genes. The mainstay of current therapy is the use of angiotensin-converting enzyme inhibitors and angiotensin receptor blockers, yet potential new therapies are now entering clinical trials. The 2017 International Workshop on Alport Syndrome in Glasgow was a pre-conference workshop ahead of the 50th anniversary meeting of the European Society for Pediatric Nephrology. It focussed on updates in clinical practice, genetics and basic science and also incorporated patient perspectives. More than 80 international experts including clinicians, geneticists, researchers from academia and industry, and patient representatives took part in panel discussions and breakout groups. This report summarises the workshop proceedings and the relevant contemporary literature. It highlights the unique clinician, patient and researcher collaborations achieved by regular engagement between the groups.
\end{abstract}

Keywords Alport syndrome · COL4A3 · COL4A4 · COL4A5 · Type IV collagen · Basement membrane

\section{Introduction}

The 2017 International Workshop on Alport syndrome took place in Glasgow and was formally designated as a preconference meeting prior to the 50th anniversary meeting of the European Society for Paediatric Nephrology (ESPN).

Rachel Lennon

Rachel.Lennon@manchester.ac.uk

1 Department of Pediatrics, University of Minnesota Masonic Children's Hospital, Minneapolis, MN, USA

2 Department of Medicine, Royal Melbourne Hospital, Victoria, Australia

3 Wellcome Centre for Cell-Matrix Research, Division of Cell Matrix Biology and Regenerative Medicine, School of Biological Sciences, Faculty of Biology Medicine and Health, University of Manchester, Manchester, UK

4 Alport Syndrome Foundation, Phoenix, AZ, USA

5 Nuffield Department of Primary Care Health Sciences, University of Oxford, Oxford, UK
Following on from the previous highly successful workshops in Oxford (2014) [1] and Göttingen (2015) [2], the meeting brought together patients, researchers, clinicians and industry participants from across the world. This review of the workshop proceedings and the contemporary literature highlights the key updates in the following dominant themes that were

6 Renal Medicine, Royal Infirmary, University of Edinburgh, Edinburgh, UK

7 Clinic of Nephrology and Rheumatology, University Medicine Goettingen, Goettingen, Germany

8 Department of Clinical Genetics, Guy's \& St Thomas' NHS Foundation Trust, London, UK

9 Division of Nephrology, Washington University School of Medicine, St Louis, MO, USA

10 Alport UK, Tetbury, UK

11 Department of Paediatric Nephrology, Royal Manchester Children's Hospital, Manchester University Hospitals NHS Foundation Trust, Manchester Academic Health Science Centre, Manchester, UK 
covered in depth during the 3-day workshop: clinical science and registries, genetics, basic science and the patient perspective.

\section{Clinical science and registries}

A large portion of the workshop was focussed on the clinical care of patients with Alport syndrome including care at specific critical junctions such as diagnosis, transition to adult care and pregnancy (Fig. 1). Dr. Rachel Lennon reviewed the diagnostic evaluation of children with persistent haematuria including the importance of obtaining a thorough family history. She also discussed the importance of recognising the diversity of Alport syndrome phenotypes and the role of genetic testing in diagnosis to avoid the need for an invasive kidney biopsy. Individuals presenting with early severe disease may have mutations in additional genes affecting the glomerulus such as MYO1E [3]. Dr. Lennon also reviewed the increasingly recognised phenotype of nephrotic syndrome with focal segmental glomerulosclerosis on kidney biopsy caused by mutations in type IV collagen genes [4].

Once a diagnosis of Alport syndrome is made, the next step is determining a plan for follow-up and treatment. These topics were reviewed by Drs. Clifford Kashtan and Oliver Gross. Screening for non-renal manifestations of Alport syndrome is important. Audiology evaluations are recommended once males with X-linked Alport syndrome (XLAS) or males and females with autosomal recessive Alport syndrome (ARAS) are 56 years of age. Anyone with type IV collagen mutations and overt proteinuria or clinical concern for hearing loss should have formal audiology evaluations. Ophthalmologic manifestations of Alport syndrome generally develop after adolescence, and screening for males with XLAS or males and females with ARAS should begin at age 15-16 years or sooner if symptomatic. Recommendations for the treatment of Alport syndrome were published in 2013, and these remain the standard of care [5]. Based on retrospective registry data, renin-angiotensin aldosterone system (RAAS) blockade is recommended at the onset of proteinuria regardless of genotype. For individuals with severe mutations or family history of early (age $<30$ years) end-stage kidney disease (ESKD), then treatment may be considered when patients are persistently microalbuminuric. Dr. Gross's phase III randomised placebo controlled study of ramipril treatment in children at very early stages of Alport syndrome (isolated haematuria or microalbuminuria) remains ongoing and is expected to report after 2019 [6]. The results of this trial will help to determine if RAAS inhibition should be recommended at even earlier ages to slow the progression of chronic kidney disease.

Alport syndrome is often diagnosed in childhood, necessitating the transition of care from a paediatric to adult nephrologist. Drs. Arvind Nagra and Neil Turner reviewed the successful 'Ready Steady Go' transition program in the UK [7].

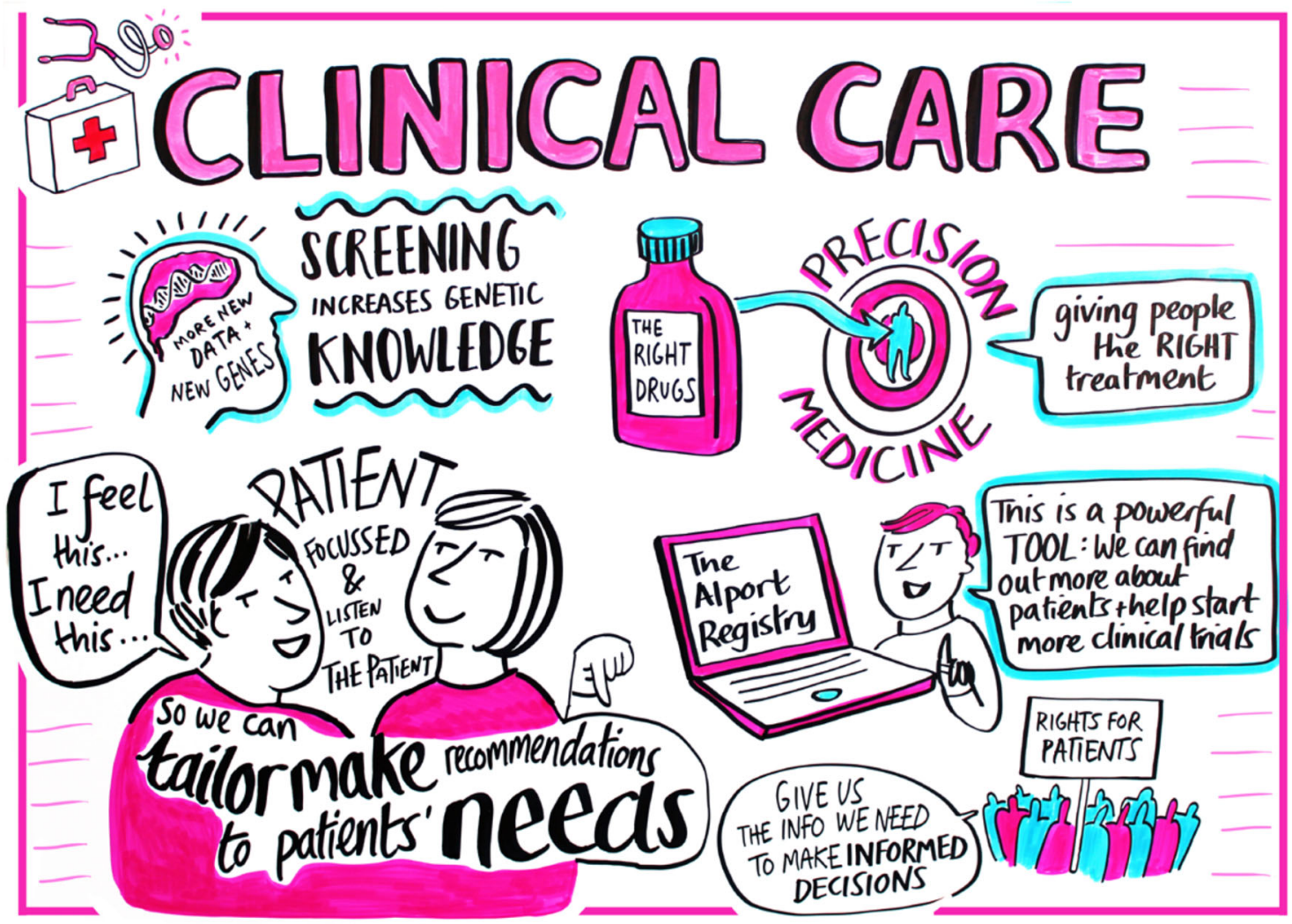

Fig. 1 Clinical care in Alport syndrome. The presentations covered patient registries, precision medicine, genetic screening and clinical trials 
This program of educational materials and readiness assessments provides a formal way to ensure smooth transition of children with kidney disease, including children with Alport syndrome. Pregnancy is also an important time of life for women with Alport syndrome; however, little is known about outcomes for women with this disorder [8]. Dr. Matt Hall reviewed outcomes for women with chronic kidney disease at the time of pregnancy and discussed improvements in both maternal and foetal outcomes over the past several decades [9]. Importantly, he reviewed the risks of RAAS inhibition in pregnancy as these are commonly utilised drugs in this population and known to be teratogenic.

Despite widespread use of RAAS inhibition, patients with Alport syndrome are still at risk for progression to ESKD, highlighting the need for clinical trials of novel agents in this population. Prior to initiation of clinical trials, a detailed understanding of the natural history and clinical and biomarker risk factors for progression is necessary. A number of Alport syndrome registries are established around the world and provide valuable natural history information. In addition, an international natural history study of patients with Alport syndrome recently completed follow-up (ATHENA study NCT02136862). At the clinical science breakout session, the group reviewed the current status of each of the registries and agreed to further discussion of a recommended common dataset of information to guide new registry formation and facilitate data sharing between registries. In addition, some of the preliminary data from the ATHENA study was reviewed and publication of results is expected in 2019. The first clinical trial specifically in patients with Alport syndrome started enrolling in 2017. This randomised, placebocontrolled trial of the NF- $\mathrm{KB}$ inhibitor bardoxolone (NCT03019185) is a landmark for the Alport research and patient communities, and additional clinical trials are in various stages of planning.

The future of Alport syndrome treatment is bright. Dr. Daniel Gale reviewed the complex pathway of bringing a new drug to market including phase 1,2 and 3 clinical trials; approval and marketing; and cost considerations. Specific challenges for clinical trials in Alport syndrome include the rare nature of the disease for successful recruiting into clinical trials as well as potential high costs of therapy for patients if a drug is approved. Dr. Michelle Rheault reviewed the importance of understanding the molecular pathways of glomerular filtration barrier dysfunction in Alport syndrome including molecular and cellular changes in podocytes and endothelial cells in response to mechanical strain, as well as changes in composition of the glomerular basement membrane (GBM) [10]. A number of agents are in clinical development for non-Alport syndrome indications that may be appropriate for use in this population based on molecular targets of drug action. For example, endothelin-1 appears to be upregulated in Alport glomeruli in response to mechanical strain and may be targeted by endothelin-1 receptor antagonists currently in development [11].

\section{Genetics}

The presentations on genetics and diagnosis of Alport syndrome demonstrated that our understanding of the value of genetic testing in Alport syndrome has increased greatly over the past 18 months (Fig. 2). In many centres, gene testing has replaced renal biopsy for the diagnosis of Alport syndrome [12]. Identifying the underlying mutation(s) indicates the mode of inheritance, enabling the targeted genetic testing of other family members who may be at risk, as well as sometimes predicting the age at onset of ESKD [13]. Furthermore, some therapies may be specifically targeted at people with missense or nonsense variants in the future.

In addition, COL4A3, COL $4 A 4$ or COL4A5 mutations are found in $10-30 \%$ of patients with focal and segmental glomerulosclerosis (FSGS) [4, 14], and Dr. Moin Saleem reported that some patients with features consistent with steroidresistant nephrotic syndrome had COL4A variants on screening with a 70-gene renal panel.

Genetic and non-genetic factors influence the prognosis to a far greater extent than thought previously. Drs. Roser Torra and Alessandra Renieri presented data suggesting that COL44 mutations result in a more severe phenotype than COL $4 A 3$ mutations. In their experience, up to one third of patients with heterozygous $C O L 4 A 4$ mutations developed renal impairment at an average age of 56 years. In addition, there is now evidence for testing for coincidental mutations in NPHS2, MYH9 and ACTN4, which all influence proteinuria $[3,15,16]$. In Dr. Constantinos Deltas' experience, up to $16 \%$ of individuals with a heterozygous $C O L 4 A 3$ or COLAA4 mutation develop renal impairment and $41 \%$ have FSGS. The p.R229Q variant in NPHS2 predisposes to increased proteinuria and renal failure, and the Rictor gene component of the $\mathrm{mTORC} 2$ pathway may be a further modifier of renal function.

For men with XLAS, and men or women with ARAS, the genetic results strongly predict outcome $[17,18]$, although the clinical course may be modified significantly by screening and early ACE inhibitor treatment $[19,20]$. The debate about an appropriate nomenclature for individuals with a heterozygous COL4A3 or COL4A4 mutation or a woman with a COL4A5 mutation continues [21]. For women with a heterozygous COL4A5 mutation, or anyone with a heterozygous COL4A3 or COL4A4 pathogenic variant, our ability to predict the future is more constrained, but these individuals should all undergo life-long renal surveillance [22]. Published data on the risk of ESKD are skewed by ascertainment bias, with an overrepresentation of people with ESKD in hospital-based series. The risk of ESKD is probably lower in women with a COL4A5 mutation than historical data suggest, but still higher 


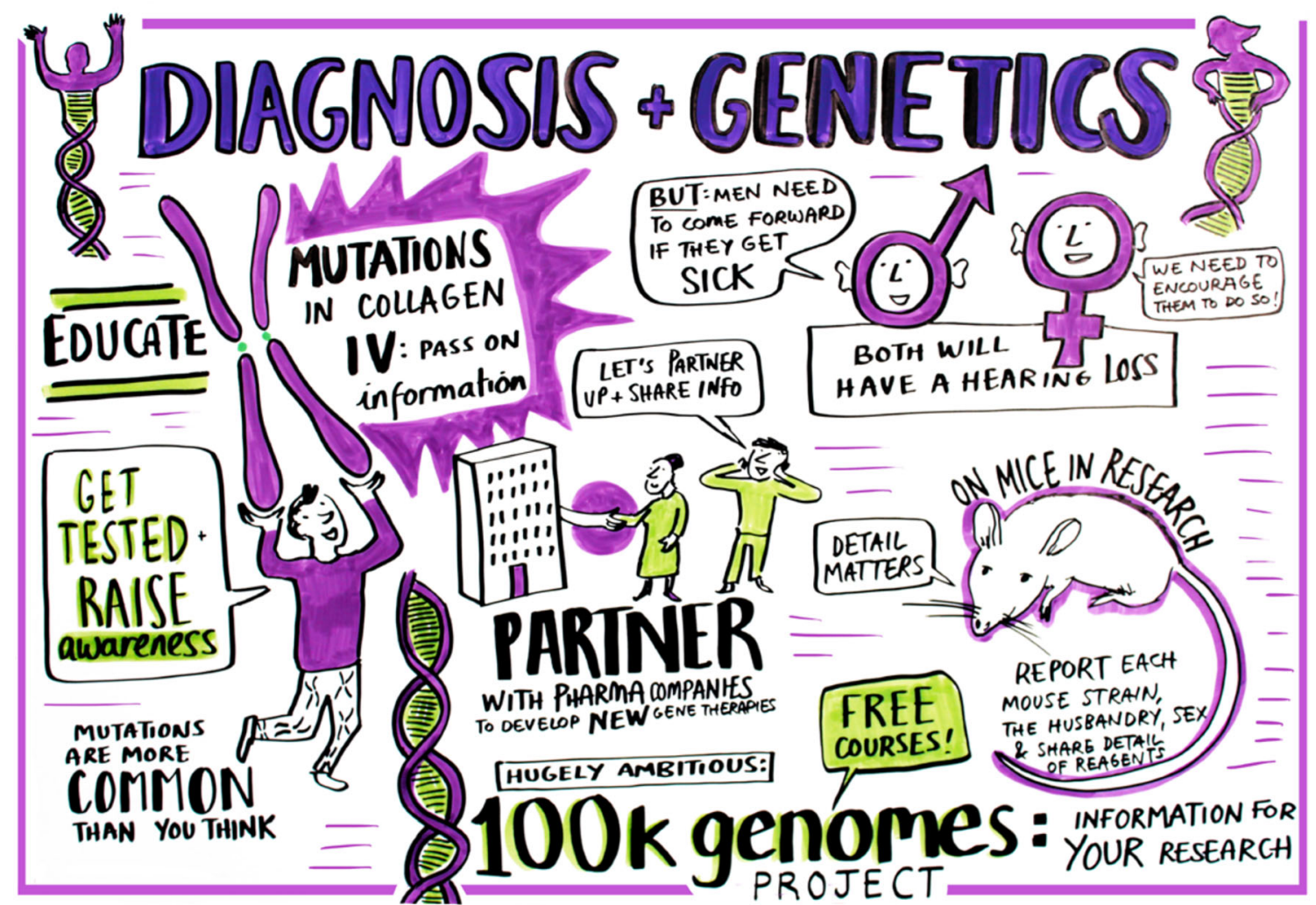

Fig. 2 Diagnosis and genetics. The importance of education and raising awareness was discussed together with the classification of Alport syndrome. Genomic sequencing projects such as 100,000 (100 k) genomes in the UK will help inform about the frequency of Alport gene mutations

than in individuals with a pathogenic heterozygous $C O L 4 A 3$ or COL4A4 variant.

Some congress participants subscribed to the view that anyone with a heterozygous COL4A3 or COL4A4 mutation should be diagnosed with Alport syndrome, to ensure that the significance of their diagnosis is appreciated and to ensure aggressive management and long-term monitoring [21]. Others, while agreeing on the need for life-long follow-up, do not classify people with a single mutation as having Alport syndrome, because of their lesser risk of ESKD and absence of extra-renal manifestations. If every person with a heterozygous COLAA3 or COL4A4 mutation were labelled with the diagnosis of Alport syndrome, its incidence would increase from the current level of 1 in 5-10,000 to as high as 1 in 100 [23, 24], with ESKD being uncommon. At the meeting, there was, however, unanimous agreement about the need for long-term monitoring, screening of other family members and a low threshold for prescribing ACE inhibitors to treat proteinuria or hypertension. Clearly, more comprehensive genotype/phenotype data are needed to enable an objective calculation of the risk of renal impairment in heterozygous carriers. Single mutations are significant susceptibility factors for renal impairment in later life, but other factors, including lifestyle attributes such as obesity, diabetes, exercise, untreated hypertension and proteinuria, are important too. Pregnancy-associated hypertension represents a risk factor in women with heterozygous COL4A5 mutations, and close monitoring is required throughout each pregnancy.

Whole-exome and whole-genome studies are identifying many more genetic variants in Alport genes, but this abundance adds to the work of confirming pathogenicity. The American College of Medical Genetics Guidelines for the classification of variants are very clear [25], and their universal adoption, together with submission of variants to the Leiden Open Variation Database (LOVD) or other databases, will help us understand the significance of individual variants better, especially heterozygous variants in the COL4A genes.

\section{Basic science}

As with previous Alport workshops, there were exceptional speakers who delivered talks regarding fundamental research relevant to Alport syndrome (Fig. 3). Dr. Billy Hudson, from Vanderbilt Medical Centre, gave an impassioned talk where he emphasised the critical importance of understanding the basic molecular mechanisms governing the 'molecular rope' formed by the three type IV collagen alpha chains that, when defective, cause Alport syndrome. His research group recently investigated type IV collagen at the evolutionary dawn of metazoan tissues by utilising Ctenophora. This is due to Ctenophora being one of the earliest branching extant animal 


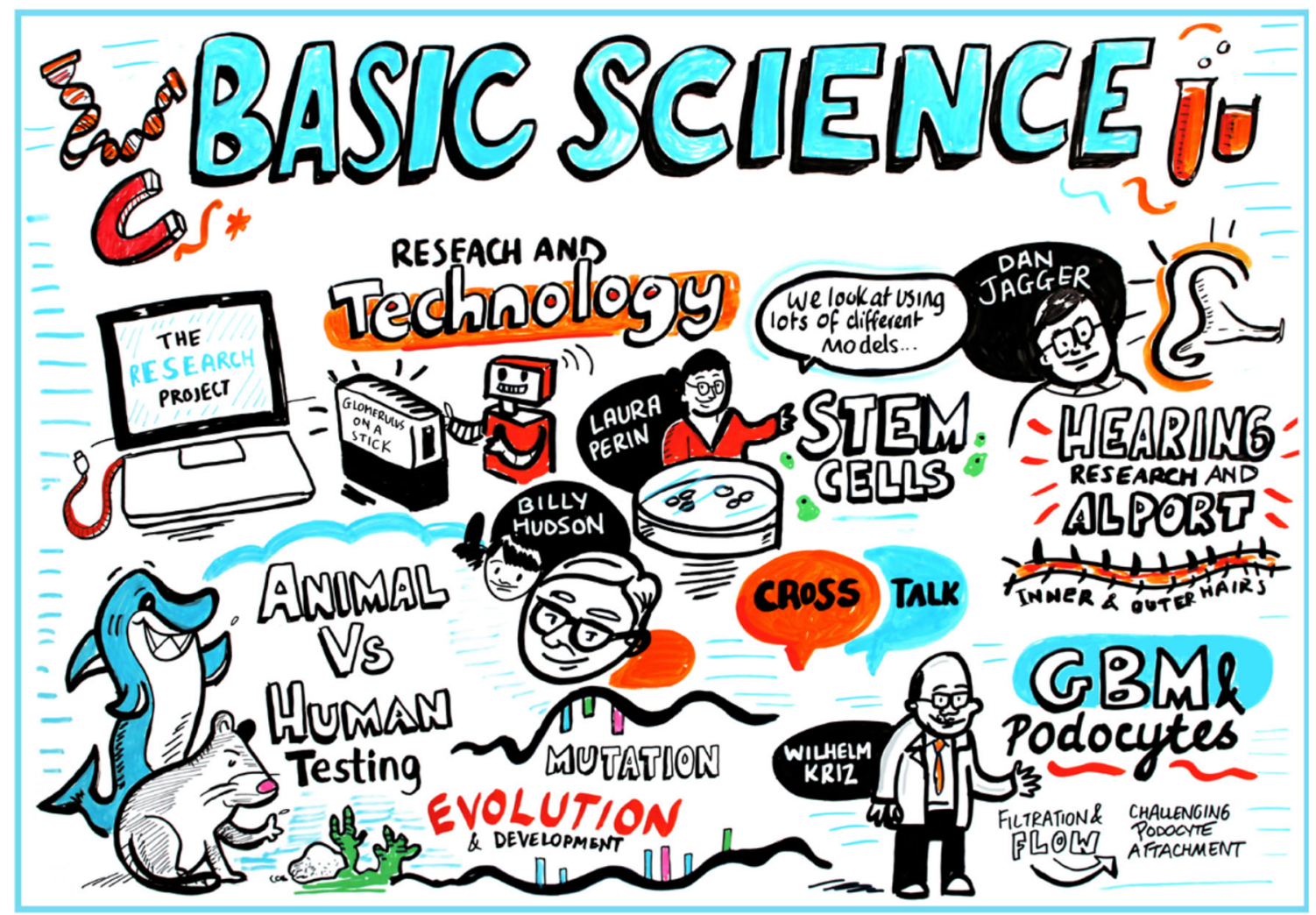

Fig. 3 Basic science. The presentation covered the different experimental systems in use to investigate the biology of type IV collagen and basement membranes. There was a focus on the mechanisms of hearing loss in Alport syndrome

phyla. Their studies revealed that type IV collagen is present in Ctenophora but absent in unicellular sister-groups, thus suggesting that type IV collagen is one of the fundamental architectural units for multicellular tissue genesis [26]. Dr. Hudson stressed the key role of protein-protein interactions, not only intra-type IV collagen interactions but also of the interactions of type IV collagen with other basement membrane (BM) components, including laminins and nidogens, in addition to cell surface receptors such as integrins.

Dr. Wilhelm Kriz followed up Billy Hudson's talk by first presenting data on the mesangium as a 'dumping ground' for defective and degraded glomerular BM (GBM) material. Evidence from the 1970s suggests that the GBM is turned over approximately every 65-100 days [27], and undoubtedly, this turnover is essential for a normal functioning GBM. Dr. Kriz demonstrated, using transmission electron microscopy (TEM), in addition to staining for specific GBM markers, that the mesangial matrix contains turned over GBM material. Furthermore, he showed evidence that increased production and defective degradation of GBM during diabetic nephropathy $(\mathrm{DN})$ contributes towards mesangial matrix expansion [28]. He then drew parallels between DN and Alport syndrome by analysing Alport patient TEM samples. Dr. Kriz hypothesised that the defective GBM component in Alport syndrome is likely to be shunted to the mesangial compartment in a mechanism similar to that seen in DN. This process may have an important role in Alport syndrome, leading to expansion of the mesangial matrix compartment and eventual loss of glomerular function. Interestingly, Dr. Kriz went on to explore the role of mechanical force within glomeruli and the consequent impact on Alport pathology. The glomerular capillary wall is exposed to high flow rates causing sheer stress [29]. The GBM is known to create the main wall tension during glomerular filtration; however, this causes the GBM to expand, and at a critical point, the GBM can no longer cope with the forces involved. Therefore, contraction of podocytes $[30,31]$ and mesangial cells [32] is required to contribute to withstand the forces across the glomerular capillary wall. Dr. Kriz described how the location of podocytes, attached to the outside of the GBM, leaves them susceptible to detachment and loss from the glomerulus in the urine. Moreover, podocytes located close to the hilum are more susceptible to this process because of the high flow rates; it is likely that podocytes that detach here cause a local increase in force that prevents reattachment [29].

Dr. Oliver Gross presented work from his laboratory exploring the role of environmental modifiers of glomerular disease such as obesity, high calorie intake and high sodium, in addition to treatment with angiotensin-converting enzyme inhibitors, the most common treatment for Alport patients 
(Fig. 4). Mouse models of both steroid-resistant nephrotic syndrome and Alport syndrome are being used, and this approach has the potential to discover the efficacy of the standard treatment for Alport syndrome taking into account many environmental factors.

Mouse models and human patient data are the most frequently used in the Alport research community, which has led to major discoveries in the past 30 years. However, both higher throughput systems including zebrafish, which have utility for high throughput screens and high-resolution in vivo imaging, and larger mammalian models of Alport syndrome are required to bridge the gap in Alport research. Dr. Mary Nabity is studying a canine model of XLAS. These animals have a lifespan of around 1 year, and Dr. Nabity has analysed RNA-seq samples collected at clinical milestones of glomerular disease development in these animals [33]. From this study, Dr. Nabity has discovered new genes that are differentially expressed between the slow and rapid progressing animals with Alport syndrome, including lysyl oxidase (LOX) transcripts. Further studies into the role of these transcript changes may provide powerful insight into the mechanisms leading to slow or rapidly progressing Alport syndrome. Another key area of research pertinent to Alport syndrome is regenerative medicine. In recent years, there has been tremendous progress in the generation of protocols for the differentiation of stem cells into renal progenitors and kidney organoids [34, 35]. Dr. Laura Perin is seeking to apply regenerative medicine to derive a treatment for Alport syndrome. She has developed systems involving stem cells taken from amniotic fluid [36] and has discovered a potential role for extracellular vesicles, produced by stem cells, in modulating vascular endothelial growth factor (VEGF) signalling in glomerular pathobiology. Deeper understanding of this process may indeed lead to potential drug targets in Alport syndrome.

Protocols for isolating and culturing podocytes from urine have been employed in a number of studies [37], and although known to be challenging, these approaches enable researchers to gain insights into podocyte biology. Dr. Sergio Daga, from The University of Siena, has been using this approach to isolate podocytes and subsequently use CRISPR gene editing technology to study Alport syndrome. This area of research has the potential to unlock further mechanistic insights in Alport syndrome.

The therapeutic potential of anti-miR-21 for the treatment of Alport syndrome was first investigated by Dr. Jeremy Duffield and colleagues in 2015 with promising results [38]. Dr. Tsubasa Yokota from Dr. Hirofumi Kai's laboratory has been building on some of these findings from this study. STAT3 and IL6 were found to be increased in mice with Alport syndrome before anti-miR-21 treatment; the group, therefore, investigated the impact of STAT3 and IL6 inhibitors in Alport mice. They found that STAT3 inhibition reduced proteinuria, whereas IL6 inhibition had no effect on this metric of glomerular function [39]. This is not the only treatment that the group have tested in Alport mice; bromide supplementation was also tried, as Billy Hudson had shown bromide to be important for type IV collagen network formation [40]. However, bromide supplementation exacerbated Alport pathology [41]. Dr. Kai's research group investigations into both the repurposing of licensed drugs, including metformin, and novel therapies are of vital importance for the Alport community.
Fig. 4 Factors that influence the progression of Alport syndrome. Treatments that have confirmed or proposed effects on protecting kidney function, cardiovascular risk and hearing (top half in green) and factors that are known or thought to be deleterious (bottom half in blue). ACE angiotensin-converting enzyme, $\mathrm{ARB}$ angiotensin receptor blocker, HMG-CoA $\beta$-hydroxy $\beta$-methylglutaryl-CoA, NSAIDs non-steroidal anti-inflammatory drugs

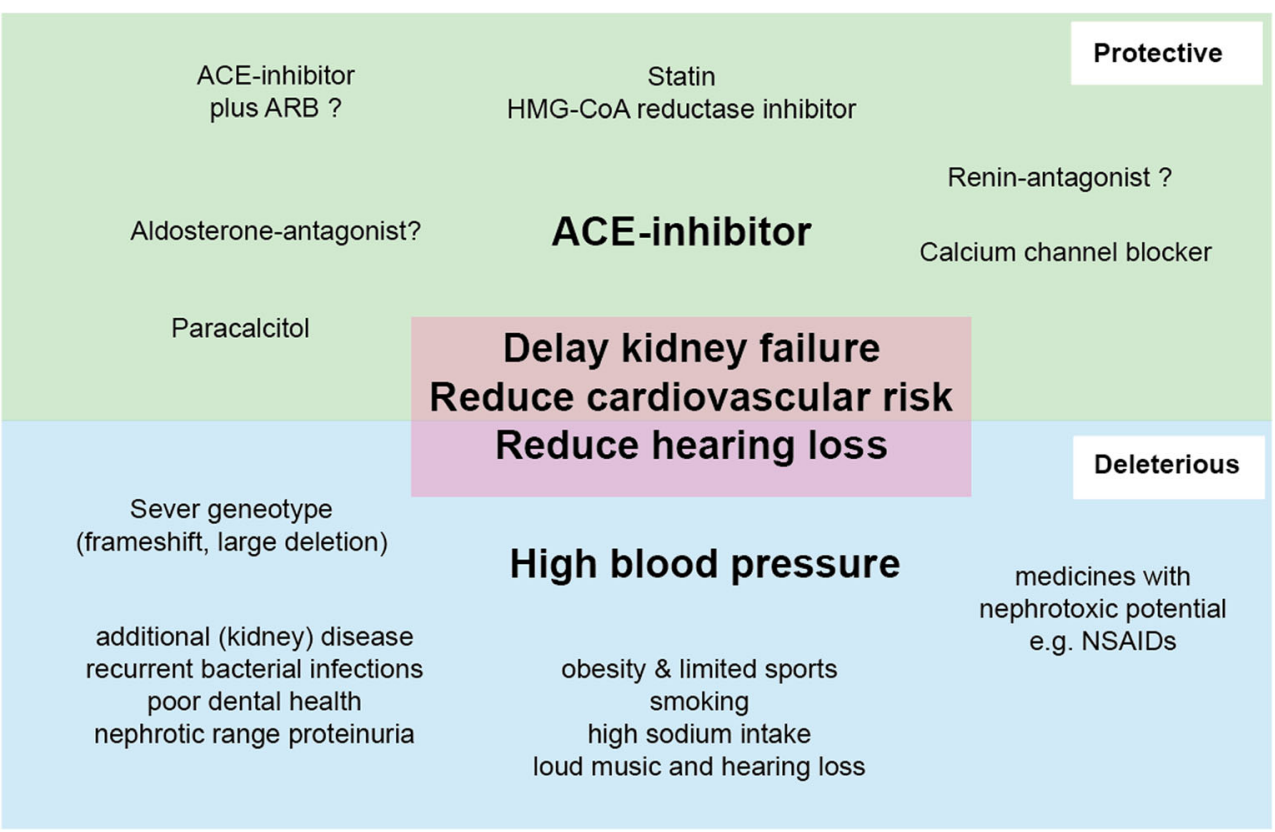


Despite renal pathologies being the focus of the Alport workshop, there is a desperate need for more research into the hearing impairment caused by Alport syndrome. Dr. Dan Jagger, from University College London, delivered a talk to provide some insights into the sensorineural hearing loss found in individuals with Alport syndrome. It is known that hearing loss occurs in Alport syndrome, but there is no evidence for a disorder in balance, which may be anticipated if there is progressive damage to the inner ear. The structure thought to be most likely progressively damaged in Alport patients is the basilar membrane of the cochlea. The basilar membrane sits on a basement membrane which is composed of type IV collagen a3a4a5. Both inner and outer hair cells of the cochlea are exposed to forces, which in turn are converted to electrical signals interpreted by the brain as sound. Evidence suggests that it is the outer hair cells that are damaged in Alport syndrome. The outer hair cells are the 'amplifiers' of the signal generated by the inner hair cells, which is why a 'base level' of hearing that can be amplified with hearing aids remains in individuals with Alport syndrome. Although it is uncertain whether the hearing loss phenotype is present in all mouse models with Alport syndrome, Dr. Jagger warned about the future of hearing research in Alport mice, as it is well known that there is age-related hearing loss in mice, which may confound studies. The most obvious current advice to patients with Alport syndrome is to avoid exposure to mechanical damage, for instance use of head phones.

\section{Patient perspectives}

Representatives from National Patient Organizations were in attendance from Australia, China, France, Germany, Italy, The Netherlands, Spain, the UK and the USA. In addition to attending the main session, a pre-event meeting took place with these groups to discuss how they could better collaborate with each other to provide improved resources and support to patients and encourage research. The creation of an International Alport Organization was discussed to achieve this and elements of this organization were captured by the meeting illustrators. It was agreed that there are significant challenges to the creation of such an organization. Amongst these were:

- Dependence on volunteers for organization and resources.

- Significant differences in treatment resources and needs between different countries.

- Differences in effective communication modes.

- Differences in cultural attitudes towards disease, privacy and the physician-patient relationship
These challenges closely mirror those posed to creation of an International Alport Patient Registry discussed in past workshops. Susie Gear of Alport UK proposed a series of potential logos for an International Alport Organization (Fig. 3).

Recognising the importance of the patient perspective in research and the development of potential therapies, patients were asked to share their stories with the larger group (Fig. 5). Andre Weinstock from the USA shared his experience as a patient who had a transplant and continues to experience hearing loss. This led to a discussion about the role of hearing loss in Alport syndrome as an important quality of life concern. Jessie Zhang, a mother of an Alport patient from China, spoke about the need for patients to connect with each other as part of a community to alleviate feelings of isolation, gain knowledge and resources, and work together for advocacy. The Alport Collective, a group of teenage patients from the UK, shared videos they created to improve communication among teens about Alport syndrome, and these are accessible on YouTube: https://www.youtube.com/watch?v= Ps3rMpx7YZg, https://www.youtube.com/watch?v= $5 \mathrm{gJEtmhcClU}$. Maria Jose, from Spain, spoke of the patient advocacy organization's efforts to unite their community. While each journey was different, all conveyed the importance of having a community to provide support and resources.

In addition, patient groups play a critical role in research and the development of potential therapies. These groups are instrumental not only in recruiting patients for research but also conveying the patient perspective to researchers and industry. Gina Parziale, Executive Director of the Alport Syndrome Foundation in the USA shared their plans for an Externally Led Patient Development Meeting. It took place in San Diego in October 2018 and brought together patients and their care-partners, representatives from the US Food and Drug Administration (FDA), pharmaceutical companies interested in developing drugs for the disease, and physicians - all to hear from patients about Alport syndrome. In these meetings, the patient's experience is brought to the forefront for governmental regulatory bodies, pharmaceutical companies and academic researchers to understand.

\section{The Healthtalk project on Alport syndrome}

As a further expansion of the patient voice, the meeting also heard about the Healthtalk project on Alport syndrome. The importance of listening to patient experiences is central to formulating health policy in the UK (and many other countries) [42]. Research suggests that hearing other people's experiences, alongside 


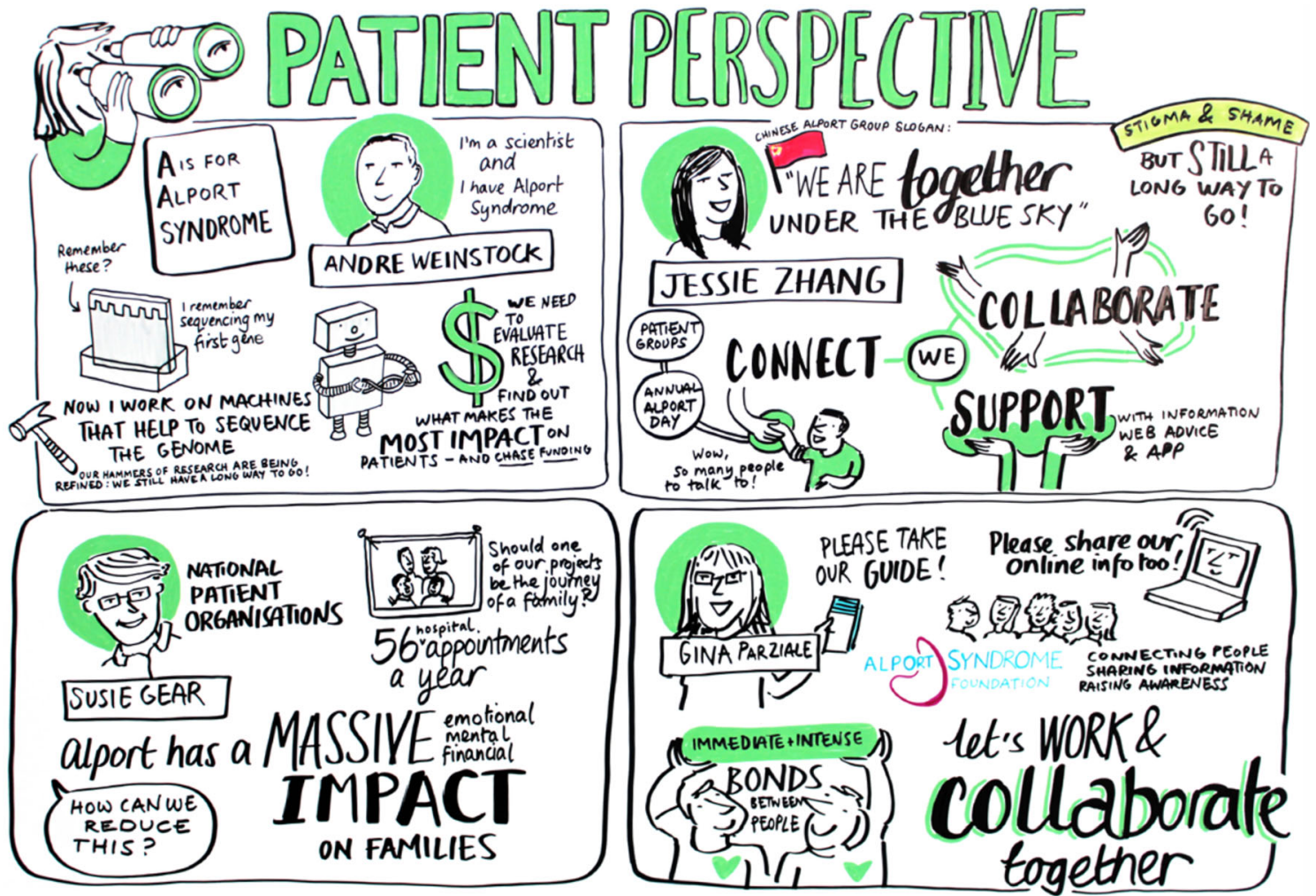

Fig. 5 Patient perspective. Four presentations from members of Alport syndrome patient organisations highlighted the importance of the patient voice

factual information, engages people's attention and influences and supports treatment decision making [43, 44].

From 2015 to 2017, a research project collaboration between Alport UK and the University of Oxford led to a freely accessible resource on Alport syndrome at the website Healthtalk.org. Based on rigorous qualitative research, Healthtalk provides a multi-media internet resource on the experiences, information and support needs of people with different health issues. The site already features 110 different conditions, had more than 6 million visitors in 2018 and is based on more than 4,000 in-depthnarrative interviews of peoples' experiences of health and illness. Health conditions on the site include several major cancers,cardiovascular disease, mental health, epilepsy, rheumatoid arthritis, pregnancy, screening, sexual health and experiences of carers ofpeople with dementia. The interviews are generated and analysed by experienced social science researchers, most of whom are based in the Health Experiences Research Group within the University of Oxford's Nuffield Department of Primary Care Health Sciences www.phc.ox.ac.uk/research/health-experiences. Dr. Melissa Stepney (co-author) conducted the interviews and analysis for the section on Alport Syndrome. The Healthtalk sections have direct relevance for health and social care professionals and students, schools, undergraduate and post-graduate learning and teaching.

Further, the website section on Alport syndrome provides an evidence base for patients and the public, learning and teaching, policy makers, all who want to consult a balanced, patient-led collection of experiences. Here, narrative interviews were conducted with 38 people with Alport syndrome, including families and partners, and 3 interviews with healthcare professionals with expertise on Alport syndrome. The patient interviews offer in-depth knowledge and firsthand experiences of what it is like to actually live with Alport syndrome. On the site http://healthtalk.org/peoplesexperiences/long-term-conditions/alport-syndrome/overview, there are around 27 topic summaries with 250 video clips chosen to reflect issues important to participants, such as the first signs and symptoms of Alport syndrome, getting a diagnosis of Alport syndrome, medication, reproductive choices, living as a female 'carrier' and the emotional side of living with Alport syndrome. Although this study was UK based, many of the overall experiences are similar across the world - in practice, this means that when a person with Alport syndrome looks at any of these summaries, they should find that an experience or perspective akin to their own is included, although this may not necessarily be reported by a person of the same age, family situation or social class as themselves. This baseline understanding of UK patients is 
critical in order to inform further projects and toolkits to better support patients in the future, including improving communication, more effective and efficient clinical care, much needed mental health support and the treatment of female 'carriers'.

\section{Summary}

Overall, this review highlights the current and significant developments in Alport syndrome research from clinical and basic science to genetics and qualitative research with patients. The collaboration between clinicians, patients and researchers is key to accelerating the current research efforts in order to deliver the unmet needs of patients living with Alport syndrome.

Acknowledgements The author time was supported by a Wellcome Senior Fellowship award (202860/Z/16/Z) to R.L. and a Research Project Award to R.L. from Kidney Research UK (K1199). The authors also acknowledge core funding from the Wellcome Trust (203128/Z/16/ Z) to the Wellcome Centre for Cell-Matrix Research at the University of Manchester.

\section{Compliance with ethical standards}

Conflict of interest MR receives research funding from Regulus Therapeutics and Reata Pharmaceuticals. The other authors declare no conflicts of interests.

Open Access This article is distributed under the terms of the Creative Commons Attribution 4.0 International License (http:// creativecommons.org/licenses/by/4.0/), which permits unrestricted use, distribution, and reproduction in any medium, provided you give appropriate credit to the original author(s) and the source, provide a link to the Creative Commons license, and indicate if changes were made.

\section{References}

1. Miner JH, Baigent C, Flinter F, Gross O, Judge P, Kashtan CE, Lagas S, Savige J, Blatt D, Ding J, Gale DP, Midgley JP, Povey S, Prunotto M, Renault D, Skelding J, Turner AN, Gear S (2014) The 2014 International Workshop on Alport Syndrome. Kidney Int 86:679-684

2. Gross O, Kashtan CE, Rheault MN, Flinter F, Savige J, Miner JH, Torra R, Ars E, Deltas C, Savva I, Perin L, Renieri A, Ariani F, Mari F, Baigent C, Judge P, Knebelman B, Heidet L, Lagas S, Blatt D, Ding J, Zhang Y, Gale DP, Prunotto M, Xue Y, Schachter AD, Morton LCG, Blem J, Huang M, Liu S, Vallee S, Renault D, Schifter J, Skelding J, Gear S, Friede T, Turner AN, Lennon R (2017) Advances and unmet needs in genetic, basic and clinical science in Alport syndrome: report from the 2015 International Workshop on Alport Syndrome. Nephrol Dial Transplant 32:916924

3. Lennon R, Stuart HM, Bierzynska A, Randles MJ, Kerr B, Hillman KA, Batra G, Campbell J, Storey H, Flinter FA, Koziell A, Welsh GI, Saleem MA, Webb NJ, Woolf AS (2015) Coinheritance of COL4A5 and MYO1E mutations accentuate the severity of kidney disease. Pediatr Nephrol 30:1459-1465
4. Malone AF, Phelan PJ, Hall G, Cetincelik U, Homstad A, Alonso AS, Jiang R, Lindsey TB, Wu G, Sparks MA, Smith SR, Webb NJ, Kalra PA, Adeyemo AA, Shaw AS, Conlon PJ, Jennette JC, Howell DN, Winn MP, Gbadegesin RA (2014) Rare hereditary COL4A3/ COL4A4 variants may be mistaken for familial focal segmental glomerulosclerosis. Kidney Int 86:1253-1259

5. Kashtan CE, Ding J, Gregory M, Gross O, Heidet L, Knebelmann B, Rheault M, Licht C, Alport Syndrome Research Collaborative (2013) Clinical practice recommendations for the treatment of Alport syndrome: a statement of the Alport Syndrome Research Collaborative. Pediatr Nephrol 28:5-11

6. Gross O, Friede T, Hilgers R, Gorlitz A, Gavenis K, Ahmed R, Durr U (2012) Safety and efficacy of the ACE-inhibitor ramipril in Alport syndrome: the double-blind, randomized, placebo-controlled, multicenter phase III EARLY PRO-TECT Alport trial in pediatric patients. ISRN Pediatr 2012:436046

7. Nagra A, McGinnity PM, Davis N, Salmon AP (2015) Implementing transition: ready steady go. Arch Dis Child Educ Pract Ed 100:313-320

8. Yefet E, Tovbin D, Nachum Z (2016) Pregnancy outcomes in patients with Alport syndrome. Arch Gynecol Obstet 293:739-747

9. Hall M (2016) Pregnancy in women with CKD: a success story. Am J Kidney Dis 68:633-639

10. Noone D, Licht C (2013) An update on the pathomechanisms and future therapies of Alport syndrome. Pediatr Nephrol 28:10251036

11. Dufek B, Meehan DT, Delimont D, Cheung L, Gratton MA, Phillips G, Song W, Liu S, Cosgrove D (2016) Endothelin A receptor activation on mesangial cells initiates Alport glomerular disease. Kidney Int 90:300-310

12. Savige J, Gregory M, Gross O, Kashtan C, Ding J, Flinter F (2013) Expert guidelines for the management of Alport syndrome and thin basement membrane nephropathy. J Am Soc Nephrol 24:364-375

13. Savige J, Storey H, Il Cheong H, Gyung Kang H, Park E, Hilbert P, Persikov A, Torres-Fernandez C, Ars E, Torra R, Hertz JM, Thomassen M, Shagam L, Wang D, Wang Y, Flinter F, Nagel M (2016) X-linked and autosomal recessive Alport syndrome: pathogenic variant features and further genotype-phenotype correlations. PLoS One 11:e0161802

14. Gast C, Pengelly RJ, Lyon M, Bunyan DJ, Seaby EG, Graham N, Venkat-Raman G, Ennis S (2016) Collagen (COL4A) mutations are the most frequent mutations underlying adult focal segmental glomerulosclerosis. Nephrol Dial Transplant 31:961-970

15. Tonna S, Wang YY, Wilson D, Rigby L, Tabone T, Cotton R, Savige J (2008) The R229Q mutation in NPHS2 may predispose to proteinuria in thin-basement-membrane nephropathy. Pediatr Nephrol 23:2201-2207

16. Bullich G, Trujillano D, Santin S, Ossowski S, Mendizabal S, Fraga G, Madrid A, Ariceta G, Ballarin J, Torra R, Estivill X, Ars E (2015) Targeted next-generation sequencing in steroid-resistant nephrotic syndrome: mutations in multiple glomerular genes may influence disease severity. Eur J Hum Genet 23:1192-1199

17. Jais JP, Knebelmann B, Giatras I, De Marchi M, Rizzoni G, Renieri A, Weber M, Gross O, Netzer KO, Flinter F, Pirson Y, Dahan K, Wieslander J, Persson U, Tryggvason K, Martin P, Hertz JM, Schroder C, Sanak M, Carvalho MF, Saus J, Antignac C, Smeets H, Gubler MC (2003) X-linked Alport syndrome: natural history and genotype-phenotype correlations in girls and women belonging to 195 families: a "European Community Alport Syndrome Concerted Action" study. J Am Soc Nephrol 14:2603-2610

18. Jais JP, Knebelmann B, Giatras I, De Marchi M, Rizzoni G, Renieri A, Weber M, Gross O, Netzer KO, Flinter F, Pirson Y, Verellen C, Wieslander J, Persson U, Tryggvason K, Martin P, Hertz JM, Schroder C, Sanak M, Krejcova S, Carvalho MF, Saus J, Antignac C, Smeets H, Gubler MC (2000) X-linked Alport 
syndrome: natural history in 195 families and genotype- phenotype correlations in males. J Am Soc Nephrol 11:649-657

19. Temme J, Peters F, Lange K, Pirson Y, Heidet L, Torra R, Grunfeld JP, Weber M, Licht C, Muller GA, Gross O (2012) Incidence of renal failure and nephroprotection by RAAS inhibition in heterozygous carriers of X-chromosomal and autosomal recessive Alport mutations. Kidney Int 81:779-783

20. Gross O, Licht C, Anders HJ, Hoppe B, Beck B, Tonshoff B, Hocker B, Wygoda S, Ehrich JH, Pape L, Konrad M, Rascher W, Dotsch J, Muller-Wiefel DE, Hoyer P, Study Group Members of the Gesellschaft für Pädiatrische Nephrologie, Knebelmann B, Pirson Y, Grunfeld JP, Niaudet P, Cochat P, Heidet L, Lebbah S, Torra R, Friede T, Lange K, Muller GA, Weber M (2012) Early angiotensinconverting enzyme inhibition in Alport syndrome delays renal failure and improves life expectancy. Kidney Int 81:494-501

21. Kashtan CE, Ding J, Garosi G, Heidet L, Massella L, Nakanishi K, Nozu K, Renieri A, Rheault M, Wang F, Gross O (2018) Alport syndrome: a unified classification of genetic disorders of collagen IValpha345: a position paper of the Alport Syndrome Classification Working Group. Kidney Int 93:1045-1051

22. Savige J, Colville D, Rheault M, Gear S, Lennon R, Lagas S, Finlay M, Flinter F (2016) Alport syndrome in women and girls. Clin J Am Soc Nephrol 11:1713-1720

23. Savige J, Rana K, Tonna S, Buzza M, Dagher H, Wang YY (2003) Thin basement membrane nephropathy. Kidney Int 64:1169-1178

24. Papazachariou L, Papagregoriou G, Hadjipanagi D, Demosthenous P, Voskarides K, Koutsofti C, Stylianou K, Ioannou P, Xydakis D, Tzanakis I, Papadaki A, Kallivretakis N, Nikolakakis N, Perysinaki G, Gale DP, Diamantopoulos A, Goudas P, Goumenos D, Soloukides A, Boletis I, Melexopoulou C, Georgaki E, Frysira E, Komianou F, Grekas D, Paliouras C, Alivanis P, Vergoulas G, Pierides A, Daphnis E, Deltas C (2017) Frequent COL4 mutations in familial microhematuria accompanied by later-onset Alport nephropathy due to focal segmental glomerulosclerosis. Clin Genet 92:517-527

25. Richards S, Aziz N, Bale S, Bick D, Das S, Gastier-Foster J, Grody WW, Hegde M, Lyon E, Spector E, Voelkerding K, Rehm HL, ACMG Laboratory Quality Assurance Committee (2015) Standards and guidelines for the interpretation of sequence variants: a joint consensus recommendation of the American College of Medical Genetics and Genomics and the Association for Molecular Pathology. Genet Med 17:405-424

26. Fidler AL, Darris CE, Chetyrkin SV, Pedchenko VK, Boudko SP, Brown KL, Gray Jerome W, Hudson JK, Rokas A, Hudson BG (2017) Collagen IV and basement membrane at the evolutionary dawn of metazoan tissues. Elife. https://doi.org/10.7554/eLife. 24176

27. Price RG, Spiro RG (1977) Studies on the metabolism of the renal glomerular basement membrane. Turnover measurements in the rat with the use of radiolabeled amino acids. J Biol Chem 252:85978602

28. Kriz W, Lowen J, Federico G, van den Born J, Grone E, Grone HJ (2017) Accumulation of worn-out GBM material substantially contributes to mesangial matrix expansion in diabetic nephropathy. Am J Physiol Ren Physiol 312:F1101-F1111

29. Kriz W, Lemley KV (2017) Mechanical challenges to the glomerular filtration barrier: adaptations and pathway to sclerosis. Pediatr Nephrol 32:405-417

30. Endlich K, Kliewe F, Endlich N (2017) Stressed podocytesmechanical forces, sensors, signaling and response. Pflugers Arch 469:937-949
31. Kriz W, Mundel P, Elger M (1994) The contractile apparatus of podocytes is arranged to counteract GBM expansion. Contrib Nephrol 107:1-9

32. Kriz W, Elger M, Lemley K, Sakai T (1990) Structure of the glomerular mesangium: a biomechanical interpretation. Kidney Int Suppl 30:S2-S9

33. Chu CP, Hokamp JA, Cianciolo RE, Dabney AR, BrinkmeyerLangford C, Lees GE, Nabity MB (2017) RNA-seq of serial kidney biopsies obtained during progression of chronic kidney disease from dogs with X-linked hereditary nephropathy. Sci Rep 7:16776

34. Takasato M, Er PX, Chiu HS, Little MH (2016) Generation of kidney organoids from human pluripotent stem cells. Nat Protoc 11:1681-1692

35. Takasato M, Er PX, Chiu HS, Maier B, Baillie GJ, Ferguson C, Parton RG, Wolvetang EJ, Roost MS, Chuva de Sousa Lopes SM, Little MH (2015) Kidney organoids from human iPS cells contain multiple lineages and model human nephrogenesis. Nature 526: 564-568

36. Sedrakyan S, Da Sacco S, Milanesi A, Shiri L, Petrosyan A, Varimezova R, Warburton D, Lemley KV, De Filippo RE, Perin L (2012) Injection of amniotic fluid stem cells delays progression of renal fibrosis. J Am Soc Nephrol 23:661-673

37. Krtil J, Platenik J, Kazderova M, Tesar V, Zima T (2007) Culture methods of glomerular podocytes. Kidney Blood Press Res 30: $162-174$

38. Gomez IG, MacKenna DA, Johnson BG, Kaimal V, Roach AM, Ren S, Nakagawa N, Xin C, Newitt R, Pandya S, Xia TH, Liu X, Borza DB, Grafals M, Shankland SJ, Himmelfarb J, Portilla D, Liu S, Chau BN, Duffield JS (2015) Anti-microRNA-21 oligonucleotides prevent Alport nephropathy progression by stimulating metabolic pathways. J Clin Invest 125:141-156

39. Yokota T, Omachi K, Suico MA, Kamura M, Kojima H, Fukuda R, Motomura K, Teramoto K, Kaseda S, Kuwazuru J, Takeo T, Nakagata N, Shuto T, Kai H (2018) STAT3 inhibition attenuates the progressive phenotypes of Alport syndrome mouse model. Nephrol Dial Transplant 33:214-223

40. McCall AS, Cummings CF, Bhave G, Vanacore R, Page-McCaw A, Hudson BG (2014) Bromine is an essential trace element for assembly of collagen IV scaffolds in tissue development and architecture. Cell 157:1380-1392

41. Yokota T, Omachi K, Suico MA, Kojima H, Kamura M, Teramoto K, Kaseda S, Kuwazuru J, Shuto T, Kai H (2017) Bromide supplementation exacerbated the renal dysfunction, injury and fibrosis in a mouse model of Alport syndrome. PLoS One 12:e183959

42. Gann B (2013) Understanding and using experiences of health and illness: the policy landscape. In: Ziebland S C, A., Calabrese, J., Locock, L, (ed) Understanding and using health experiences OUP, Oxford

43. Prinjha SEJ, Ziebland S, McPherson A (2011) A mastectomy for something that wasn't even truly invasive cancer. Women's understandings of having a mastectomy for screen-detected DCIS: a qualitative study. J Med Screen 18:34-40

44. Feinmann J (2011) Listening to patients' narratives can help improve quality of psychosis care. BMJ 342:d2245

Publisher's note Springer Nature remains neutral with regard to jurisdictional claims in published maps and institutional affiliations. 